\title{
Research on the Development of Sports Industry in China under the Belt-Road Initiative
}

\author{
Tao Shangwu \\ College of Physical Education, Yan'an University, Yan'an, 716000, China \\ 236488990@qq.com
}

\begin{abstract}
The Belt and Road initiative is a top-level national strategy of our country. The sports industry is becoming more and more important in China's economy. It is regarded as a new growth point for our economy. Under the stimulus and promotion of a number of industrial policies, the sports industry in China has witnessed rapid development. However, it is also facing bottlenecks such as unreasonable industrial structure, imperfect distribution and suppressed exports. The "Belt and Road" implies a broad market prospect. The sports industry in our country mainly transfers and merges sports infrastructure, sporting goods manufacturing and sports tourism, and realizes the transformation and upgrading of the sports industry.
\end{abstract}

Keywords-"Belt and Road"; Sports industry; Development

\section{INTRODUCTION}

In September 2013, during his visit to Southeast Asia and Central Asia, Chairman Xi proposed a major initiative of "One Belt and One Road", that is, building the Silk Road Economic Belt and the Maritime Silk Road. On November 8, 2014, at the Dialogue on Enhancing Partnerships for Internet Connectivity held at the Diaoyutai State Guesthouse in Beijing, Chairman $\mathrm{Xi}$ explicitly proposed the "One Belt and One Road" national inter-partnership partnership to jointly build a community of development and destiny. On March 28, 2015, President Xi focused on the keynote address of "Asia's New Future: Towards a Community of Destiny." The "One Belt and One Road" officially raised its status as a national development strategy. On November 17, 2016, "One Belt and One Road" was officially written into the resolution of the 71st UN General Assembly. On March 17, 2017, resolution 2344 adopted by the UN Security Council, for the first time, included building a "community of human destiny" as an important concept and called for all parties to urge them to promote the "Belt and Road" and regional economic cooperation [1].

On October 20, 2014, the State Council promulgated Document No. 46, and relevant departments promulgated a number of supporting policies to promote the development of the sports industry. Our sports industry also ushered in the golden period of development. On May 5, 2016, the "Thirteenth Five-Year Plan for Sports Development" was formally promulgated. The goal of "planning" is to have a sports industry scale of more than 3 trillion by 2020. Overall, the development level of China's sports industry is not yet high, the structure is not yet reasonable, and the distance from the major force for the restructuring and upgrading of the national economy is obviously different. The "Belt and Road Initiative" is a national strategy advocated by China that promotes win-win cooperation and common development under the principles of business negotiation, sharing and coconstruction and will undoubtedly provide a broader opportunity for the development of China's sports industry.

\section{THE CURRENT BotTLENECK IN THE DEVELOPMENT OF CHINA'S SPORTS INDUSTRY}

\section{A. The industrial structure is irrational}

According to relevant public data, in 2012, the total number of people engaged in the sports industry in the country was 3.7562 million. The added value of the industry was 313.595 billion yuan, accounting for $0.6 \%$ of GDP, an increase of $14.44 \%$ over 2011. In 2013, the national output value of sports related industries was 1.1 trillion yuan, and the added value of the industry was 356.3 billion yuan, up $10.82 \%$ and the proportion of GDP was $0.63 \%$.On October 46, 2014, the promulgation of the document established the status of the sports industry and made it clearer. Government departments at all levels to actively implement the No. 46 document, the development of the sports industry ushered in the golden age. On December 27, 2016, the State Sports General Administration and the National Bureau of Statistics jointly released the 2015 sports industry scale and value-added data in 2015. The total output value of sports industry in 2015 was $1,710.7$ billion yuan, with added value of 549.44 billion yuan and the proportion of DDP of $0.8 \%$. Among them, sporting goods and related products accounted for the largest share of the total value-added and value-added of the manufacturing industry, with output value of 1.12382 trillion yuan and added value of 275.5 billion yuan, accounting for $65.7 \%$ of the total value of China's sports industry, accounting for $50.2 \%$ of the added value. The total output value of sports services (excluding sporting goods and related products manufacturing and sports venues) was 571.36 billion yuan, with a valueadded of 270.36 billion yuan, accounting for $33.4 \%$ and $49.2 \%$ respectively. It can be seen that in the sports industry in our country, the proportion of sporting goods and related products manufacturing industry is heavier, while that of sports service industry is relatively low. In the countries with developed sports industry, the proportion of sports service industry basically exceeds $60 \%$. Compared with the developed countries, the structure of China's sports industry is still not 
rational, especially in the competitive performance industry. Sports brand cultivation is not enough, our country is a sporting goods and related industries, many countries, many sports equipment are manufactured in China, but in the highend sporting goods market, the competitiveness of China's sports brand is still not enough [2].

\section{B. Industrial layout is not perfect}

Industrial layout refers to a country or region's industrial productivity in a certain range of spatial distribution and portfolio structure. The distribution of sports industry refers to the distribution and combination of the supply of sports products and service activities within a certain range (a country or region). Sports industry layout can be understood as a popular sports industry planning, industrial development and industrial restructuring and overall layout planning, the relationship between the sustainable development of the sports industry.

The layout of China's sports industry is still not perfect, first of all, the gap between urban and rural areas is too large, the current sports industry is mainly concentrated in large and medium-sized cities, the proportion of townships at a very small proportion of basic rural areas, physical fitness and leisure in rural areas to carry out the basic blank state. Second, the disparity between the east and the west in our country is too large. The eastern coastal areas, whether in the sports equipment manufacturing industry or the sports and fitness consumption scale, compete in the sports performance market and consume more sports products than the western regions. Most of the large-scale international events hosted by our country are in the big cities and the eastern regions, and the frequency of hosting events is much higher than in the west. Thirdly, the spatial distribution of the sports industry in cities is not reasonable enough. The sports industry is a product of the socio-economic development to a certain level. It belongs to the high-value service industry and should be laid out in the core area where population is concentrated. However, the current status quo is that a large number of stadiums and facilities are built in the new city or suburban area and can not effectively play the role of stadiums. However, due to various reasons, the old urban areas are seriously under-riddled with sports facilities and venues and inhibit the development of urban sports industry.

\section{The export of sports products is restrained}

The transfer of the sporting goods manufacturing industry in developed countries has prompted the rise of China's sporting goods manufacturing industry. Almost all the wellknown sports brands in the world have processing plants in Guangdong and Zhejiang provinces of our country. China relies on lower labor costs and sufficient production resources to undertake the transfer of resource-intensive and laborintensive sporting goods industries in developed countries. These sporting goods manufacturers do not have the corresponding product research and development capabilities, and do not have the means of market research and product marketing, but through a low production costs, the region's policy preferences to obtain a certain degree of market competitive advantage, did not grasp the core competitiveness
[3]. These processing plants earlier attracted a large amount of domestic labor force, producing sports products export earnings, but also led to the development of the domestic sports industry and promote domestic sports consumption.

Since the outbreak of the world economic crisis in 2008, our economy has been greatly affected. To get rid of the crisis, the government has successively taken various measures to maintain its sustained economic growth. According to the joint announcement by the State Sports General Administration and the National Bureau of Statistics on the scale of the sports industry and the increase of data, the total output and added value of the sporting goods and related products manufacturing industry in 2015 were respectively 1123.82 billion yuan and 275.55 billion yuan. "2016 China sports goods industry development white paper" revealed that in 2015 the added value of the sports goods industry grew by $15.8 \%$, for two consecutive years for two years to maintain two digit growth, sporting goods import and export totaled $\$ 19$ billion 4 million, down 5.38\%; a trade surplus of $\$ 17$ billion 97 million, down $4.26 \%$. Intelligence consulting data show that in 2016 1-12 months, China's sporting goods and equipment exports amounted to $\$ 9$ billion 250 million, down $12.6 \%$. The growth rate of the sports industry greatly exceeds the growth rate of GDP, but at present, the downward pressure on the economy in our country is greater. At the same time, with the increase of labor costs, the price of resources and materials, the fluctuation of exchange rate, the labor-intensive sporting goods industry will suffer more many challenges, the export of sporting goods in China will inevitably be suppressed.

\section{OPPORTUNITY FOR DEVELOPMENT OF SPORTS INDUSTRY IN CHINA UNDER THE BELT AND ROAD}

\section{A. New Source of Scale Increment in Sports Industry}

The "Belt and Road Initiative" is a historic initiative proposed by Chairman $\mathrm{Xi}$ and will also become a new growth point for the world's economy today. At present, China and many other countries along the "Belt and Road" are extensively cooperating in politics, culture and economy, and they have become important partners with each other. At the same time, China is very friendly in providing advanced technology and loans to countries along the "Belt and Road". This is unusual and unique under the current unstable economic and political conditions in the world. The "One Belt One Road" initiative calls for the "five links" of policy communication, financial intermediation, trade liberalization, facility connectivity and people's mutual support so that China and other countries along the line can develop into a win-win partnership of mutual trust and cooperation. At the same time, through the construction of infrastructure, the development of trade relations has promoted the growth of the employed population in the countries along the line, promoted the economic development, and brought positive changes to the politics and economy of the world. The internationally recognized sports industry is the most dynamic and highlypenetrating and stimulating sunrise industry, and is an important new carrier for promoting employment and stimulating economy. The "One Belt, One Road" proposed by 
China has become a veritable development road. Economic cooperation will blossom everywhere. It will also bring tremendous impetus to the development of China's sports industry and become an important source of the incremental size of the sports industry.

\section{B. New Impetus to Perfect Sports Industry System}

The open, balanced, inclusive and inclusive regional economic cooperation framework of "One Belt and One Road" has injected new impetus into the improvement of China's sports industry system. The law of international industries shows that the industrial structure has the tendency of going from one industry to two industries and finally entering the tertiary industry. In recent years, the proportion of tertiary industry in the industrial structure in China has shown a clear trend of increasing. In 2013, it surpassed the secondary industry for the first time in 2013, reaching $48.2 \%$ in 2016, the tertiary industry added value accounted for $51.6 \%$, is the veritable of the largest industry. The supply-side reform of China's industrial structure will effectively resolve the current situation of the ineffective supply in the sports industry and the insufficient supply of the sports service industry, making the industrial structure more reasonable.

The resources along the Belt and Road are highly complementary to each other and the space for cooperation among them is huge. Domestic sports product manufacturers can shift their labor-intensive manufacturing industries to the outside world while boosting the supply of sports goods to enterprises through increasing product development and innovation in the country High-end upgrade. The northern route of "Belt and Road" is through Russia and Germany to Northern Europe. The end of the middle line is Paris. The sports service industry in developed European countries accounts for a very high proportion of the sports industry. Some countries account for $80 \%$ of the added value of the sports industry, all five major football leagues in Europe. With the development of "Belt and Road", the advanced foreign sports events management, sports, fitness and leisure, and sports science and technology services will quickly and directly enter the country and the overall development of China's sports organization and management, sports agencies and sports training will be promoted in an all-round way. Make up and improve China's sports industry system.

\section{Market as the main growth of new opportunities}

The Belt and Road Initiative is open to cross-continents and connect Asia-Europe "circle of friends," so that all interested countries can join the "circle of friends." The "One Belt One Road" initiative put forward more than three years of progress and achievements in multilateral cooperation far exceeding expectations. In 2016, the total volume of trade between China and the "Belt and Road" countries was $\$ 953.59$ billion, an increase exceeding the overall growth rate of China's foreign trade. Optimistic estimates in 2025, China's trade with the countries along the line will reach $\$ 3.8$ trillion, the minimum can reach $\$ 2.6$ trillion. The rapid development of China's trade and the country's trade along the "Belt and
Road" will open a rapidly rising channel for trade in the sports industry and promote the sustained growth of trade in the sports industry.

On May 16, 2015, the State Council issued the Guiding Opinions on Promoting Cooperation in Manufacturing Capacity and Equipment Manufacturing in the People's Republic of China signed by Premier Li Keqiang and urged them not to simply sell the products overseas while cooperating with the countries along the lines. Instead, the overall output to different countries. Sport is an important medium of cultural exchange and also the most promising industry in the world today. The factor endowments of our country and the countries along the "One Belt and One Road" are different, and the mutual complementarities between science and technology and services are strong. The good interactive development has laid a solid foundation for the depth docking of the sports industry. In order to emerge a group of international competitiveness and strong driving force Leading enterprises, distinctive characteristics of industrial clusters and well-known brands to provide new opportunities.

\section{THE MAIN DIRECTION OF SPORTS INDUSTRY} DEVELOPMENT IN OUR COUNTRY UNDER THE BELT AND ROAD

\section{A. Sports infrastructure construction}

In 2015 the Ministry of foreign affairs and the Ministry of Commerce issued the "vision and action", "The Belt and Road" is China's strategic focus in "going out", "The Belt and Road along across 65 countries across Africa and Europe, among them, the silk road is mostly the development of Chinese home. Underdeveloped infrastructure is relatively weak, there is urgent need to accelerate investment in infrastructure, developed countries also have a need for infrastructure upgrades. The construction and upgrading of sports infrastructure is also the focus of investment, which provides a huge market opportunity for China's sports construction enterprises overseas.

\section{B. Sporting goods manufacturing industry to undertake the transfer}

China's sporting goods manufacturing industry started relatively late, but the momentum of development is very good. After the reform and opening up, China relied on the advantage of labor cost to undertake a large number of foreign orders and make the sporting goods manufacturing industry develop rapidly. The total output of sporting goods and related products manufactured in 2015 was 1.12382 trillion yuan, with added value of 275.55 billion yuan. The proportion of total output and added value of the country's sports industry was $65.7 \%$ and $50.2 \%$ respectively. The current developed countries have carried out a new layout of their own industrialization and set off a "reindustrialization" in the world At the same time, due to overcapacity, rising labor costs and lack of innovation capacity, sporting goods once appeared "shop tide", the upgrading of sports product manufacturing and restructuring is imminent. 


\section{Sports tourism industry embedded development}

Sports tourism is a brand-new tourism form based on sports resources in the new era, which is essentially different from general tourism activities. After years of development, China's sports tourism has reached a relatively high level of maturity. Sports tourism routes and products oriented to sports events, sports participation and physical landscapes have been initially formed, such as the kite festival, the ski festival, the cycling festival, the dragon boat race And martial arts festival, these sets of sports events, performing arts and sports participation in hot products and achieved good results.

\section{SUMMARY}

The demand for sports products along the "Belt and Road" is booming. At the same time, the cost of labor has obvious advantages. China's sports product manufacturing industry already has a high level of production capacity and excess capacity. The transfer of products to countries along the "Belt and Road" is China's sporting goods manufacturer Opportunities and challenges faced. Belt and Road is an economic corridor stretching across Asia, Africa and Europe.
It has the richest tourism resources in the world and is the most solid foundation for developing sports tourism. With the improvement of residents' income in China, the implementation of the national fitness program and the infiltration and development of the concept of health, the concept of consumption changes and sports tourism will have a broader market in the future. The abundant sports tourism resources along "Belt and Road" can meet the multi-level and personalized travel needs of the general public and lay a better foundation for common development and win-win cooperation with other countries along the "Belt and Road".

\section{REFERENCES}

[1] Yang Yiyong, "The Belt and Road Initiative" to Open up a New Realm for China's Opening to the Outside World. Frontline, vol.6,pp 38-41, 2017.

[2] Zheng Jian,Analysis of the development of China's sports industry under the concept of sports power. contemporary sports science and technology, vol.20, pp 65+68, 2012.

[3] Jiang Tongren and so on, "Belt and Road Initiative and China sports industry docking development path. Journal of Xi'an Physical Education University, vol.34 (02), pp.129-139, 2017. 